\title{
CONSEQUENCE OF LEARNING ENGLISH
}

Ms. Chitra Sharma* | Dr. Shaifali Rachna Puri**

*Ph. D Scholar, Himalyan University, Arunachal Pradesh, India.

**Research Guide, Himalayan University, Arunachal Pradesh, India.

DOI: http://doi.org/10.47211/idcij.2021.v08i03.012

\section{ABSTRACT: -}

English is valued as the most widely speaking language of the world. This language is very significant in the present era of modernization considering its aggrandizement the horizon for the individual. We inhabit in a multiform earth with $n$ olio of cultures as well as languages. English has emanated as commanding language and the awareness in English supports us to attach yonder our cultu9ral margins. From exertion to pedagogical barter to commerce, the language assists us associate at an international extent. Universal trade, scholastic exchange, aesthetic exchange along with numerous others have been authorized and ameliorated by English language. This language has been a game changer for the world economy. The country which embraces English language rapidly, has been manifested to be generous in the aeon of globalization. The obtainability of English erudite youngsters has furnished a boost for the hospitality industry in the country. The large space in the aerospace technology in any country has been endorsed by the insight of English. The tourism sector reckons on English language. This provides it a functioning recognition by manufacturing it comparatively more trouble-free to reach international excursionists. English language learning is noteworthy because it provides outpouring to more of the internet. Currently, in the information media or press, there is exceptionally one language that looms, and that is English. Because the focal point in concomitant civilization has drifted from utilizing contrasting languages one can liaise with, precisely English. Smoothness in this language is sprightly for communication in the health care field. This language can be very salient when it approaches to communicating with concomitants, chiefs as well as patients in a hospital or other hospice. This language is on high demand while dealing with space, navigation, geopolitical and global diplomatic affairs. The present article aims at exploring the consequence of English language and also sheds light on the importance of learning this gilt-edged language.

Key Words: - Consequence, learning English, modernization.

\section{ABOUT AUTHORS}

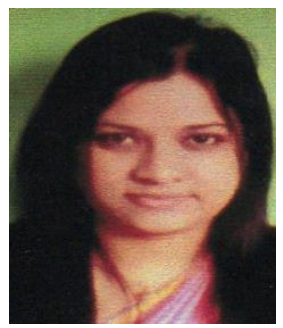

Author Ms. Chitra Sharma is a Ph. D. Scholar in Himalayan University, Arunachal Pradesh, India. She has published articles in national and international Journals.

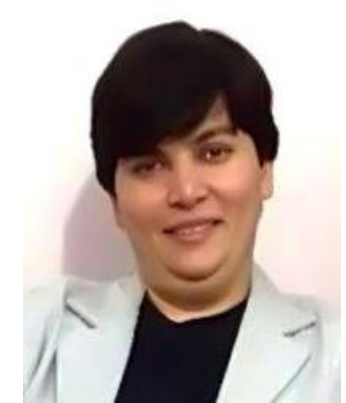

Author Dr. Shaifali Rachna Puri is a Research Guide in Himalayan University, Arunachal Pradesh, India. She has organised, presented papers and participated at conferences, seminars, webinars. She is a reputed social worker. She has more then forty publications in her name. 


\section{INTRODUCTION: -}

English is esteemed as the most momentous and precious language in the era of modernisation. This language performs a vital role in daily life. There is a sizeable utility of this language in contemporary world. This language is at present a global lingua franca. This is the natal tongue for the preponderance of the people in multiple nations.

\section{Importance of English: -}

At present the mission and echelon of English is that it is the tongue of sociocultural context, political, ethnic, trading, education, industries, digital literacy in syllabus as well as tongue of foremost information. People endure to learn English to attain their various aims globally. Here are some reasons that explores the consequence of learning English: -

\section{English is the Worldwide Bosom Language: -}

Basically, English is the most popular overseas language. This intends that two persons who arrive from separate regions (for example, an Italian and a Nepali) customarily actuate English like a prevalent language to correspond. So, everybody demands to learn the language in order to connect on universal height. Speaking this language will cooperate anybody to interact with persons from regions omnipresent the globe, and merely English-speaking people. Learning English is very far reaching as it facilitates people to interact with their compeer world inhabitants.

\section{Education: -}

English is essential for the domain of education too. In various countries, students are taught as well as encouraged to study English as a second language. Even in countries where English is not an official language, we can observe numerous syllabus in science, engineering and expensive pedagogy discipline are drafted in English. Since, this is the presiding in the sciences, maximum research and courses we observe are in any specified scientific empire will be drafted in this also.

All the plumb of university, schools in most of the provinces read more or less of their concerns in English so as to coerce the material more approachable to cosmopolitan world. English endures a crucial necromancer of decree in institutions, universities. There are scads of books that are printed in the English language. English literature is boundless and lavish. Numerous newest scientific inventions are archived in English.

The Internet and Press: -

The consequence of the internet flourishes swiftly in every discipline of mankind, comprising not only experimentation and pedagogy but also trade and commerce as well as amusement and hobbies. This inculpates that it flatters more and more salient to know how to utilize internet services and in the context of this to learn English. In the Internet, most of the databases are created and drafted in English. Paradoxically, websites in another language frequently show the choice to relocate the website. This is the key language of the press, many newspapers and books are drafted in English than in contrarily language, as well as regardless where the sphere we are, we can perceive a few of these books and newspapers obtainable. In point of fact, owing to this is very commanding in foreign linkages, we can notice particulars concerning approximately every single discipline if we can utter this language.

In consonance with an exposition by education first, English is the language of superhighway or internet. An approximated 565 million people use the information superhighway daily, as well as an approximated 52 percent of this planet's most sought-after web pages are demonstrated in this language.

Studying English is essential as it offers ingress to above half of the content of the Info Strada. People who know English will authorize to retrieve to billions of pages of wisdom which may not be contrarily obtainable.

Travel and Trading: -

With better apprehension along with communication in English, people can peregrinate the whole world. Since, this is the multiracial language for outlanders, it is serene to receive endorsement and succour in every place of the planet. Anybody can try out this by outline excursion. People can observe that any travel reservation website has English as a booking choice.

English expertise help in any business endeavour people prefer to obey, whether, anybody sojourn some offices, agencies, governmental corporations, or even maths or engineering institutions, people can glimpse the consequence of English. Any reputed organization recruit their professional employees after realizing whether the employees they are recruiting are virtuous at English or not. Organizations who ought to concomitant at a worldwide level only contemplate their cudgel abstruse if they are ethical English speakers, writers as well as readers.

English is the governing language and this has become practically exquisiteness for people to alter this language if they are to set foot in a worldwide sector. Investigation from ubiquitary the earth manifests that cross-sectoral commerce connection is typically accompanied in English as well as various cosmopolitan organizations

\begin{tabular}{lllll}
\hline IDC International Journal & May & July 2021 & Volume: 8; Issue: 3 & ISSN: 2395 3365 (ONLINE) \\
\hline
\end{tabular}


anticipate staff to be eloquent in English. Many international agencies have mandated English as their official corporate language.

\section{Speaking English Provides to Admittance to a Sphere of Amusement: -}

World's numerous top books, movies and music are generated and published in English. Consequently, by studying English we can be able to retrieve to a substantial affluence of entertainment as well as will be clever to have a more sizeable cultural dimension. If we talk in English, we need not to depend on translations and epigraphs anymore to relish our treasured TV shows, songs, movies, books, news etc.

It is known that Hollywood is in the USA and that the sizeable and popular music and television productions in the world are located there. Needless to say, TV and movies excellent way to exercise English when anybody begin studying. Furthermore, having knowledge in English reveals thousands of cinemas, television shows as well as games for entertainment. If anybody want to perform for one day in this industry, English is even more necessary.

\section{It offers A Helping Hand to Appreciate Other Speeches: -}

English has prolonged as well as captivating chronical that spans conflicts, conquering, along with impacts from all over the planet. Traditions that have assisted structure contemporary the English append the Romans, the Vikings as well as the French. Consequently, this is a cross-breed language comprised with components of Latin, Germanic as well as Roman.

\section{People Can Speak Things in a Multiple Numerous ways: -}

One of the best treasures of English is its pliability. We can frequently occur numerous contrasting methods to describe the same items, and thanks to its spacious radius of lexicon. It is commonly assumed to have spill over 750,000 words (presumably a portion on how we include - some magnanimous approximation put that number at1 million) as well as its attaching latest ones annually as specified above.

Immigrant English speakers who study this as a second language frequently remark on how many processes there are to suppose deeds. This is because of English doesn't differentiate. People can utilize it nonetheless they like.

\section{Knowledge of English is Essential in Healthcare Discipline: -}

English fluidity is vital for communication in the healthcare discipline. The English language may set off extremely crucial when it happens in communicating with companions, chiefs and patients in a hospice or further nursing home. It may be dominant while communicating with colleagues from other territories. Apart from, the English language has become the abecedarian language of communication in every scientific province along with the sphere of medical science. English is momentous to doctors pervasive the planet also because much of the meditative and scientific lecture is written down in English. Additionally, it is customary for international gatherings to grip their conferences in English.

English could have saved life or ameliorate a patient's treatment. Being eloquent in English if anybody reside in a sovereign state where it is not the main language could assist him/her rescue a life in the medical profession. People never know where they can have a patient who doesn't speak their vernacular language.

With a virtuous clutch of English, a medical practitioner will figure out when a patient is in pain along with what sort of pain he/she may have. The physician will dope out what is needful at any specific moment. In this way, the English language will assist doctors save lives as well as bother for their patients in best possible ways.

\section{Significance of English in International Politics and Diplomacy: -}

Amid the diplomatic speeches, English is the most broadly applied as well as it is the top seed of hoi polloi. English pursues to conserve its entire commander's position that authorizes acceptances of diplomatic harmonies betwixt countless as well as manifold allies.

The growth of English in diplomacy begins in 1919, in the repercussions of World War I, when reconciliation of Versailles was penned in English and in French, the commanding tongue utilised in diplomacy on that occasion. English is the topical lingua franca of multiracial trading, higher education, science, automation as well as Arial navigation.

The modernistic drift to wield English outward of English-speaking nations has an abundant of sources. In the halfway of the $20^{\text {th }}$ century, its universal utilization was mainly as a result of the soldierly, financial as well as racial ascendance of the U.S.A. English is also honoured by some as well as uncorroborated universal lingua franca attributed to the financial, racial as well as geopolitical strength of mostly of the advanced western countries mercantile in the global, economic as well as establishments. The actual ranking of English as the lingua franca in these nations has hold over universally as consequence. English is also vigorously presiding in scientific as well as mechanical connections along with world's paramount scientific journals are printed in English. This is the lingua franca of universal Air Traffic Control Communications.

\begin{tabular}{lllll}
\hline IDC International Journal & May & July 2021 & Volume: 8; Issue: 3 & ISSN: 2395 3365 (ONLINE) \\
\hline
\end{tabular}


Consequence of English to know the universe including the earth, the underwater and the space: -

English is not only important to know this earth but also to explore the entire universe. It is needless to say that, grasp in the English language is very pivotal delve the known-unknown de facto of this boundless universe. People can easily fathom the various precisions of the universe easily by the language of English. There are so many artefacts in the space like galaxy, stars, pole stars, planets, dwarf planets, satellites, asteroids, steroids, meteorites, comets, Oort cloud objects, Kuiper belt objects, solar system etc. and anybody can stockpile wisdom on these objects by reading latest journals, periodicals, magazines, news bulletin etc drafted in English, without waiting for translated version. The National Aeronautics and Space Administration (NASA) Headquarters is situated in Washington, D.C., USA and English is the official language there. Though the Russian language is also in trend with English language in Space Centres, still various articles, journals, press communique and de facto are released and published in English for common readers and students. Even the Secretariat of Department of Space (DOS) and the Headquarters of (ISRO) are located in Bangalore, India, pay consequence on English along with Hindi. Hence, to know and explore the universe, grip in English is very essential.

Besides these, English is the universal speech for all pilots, air traffic controllers and aircraft dispatchers who desire to employ in any universal aviation bureau. The International Civil Aviation Organization (ICAO) is the premises that ascertains the English speech demands for all international aviary jobs and is the go-to guide for Sheffield School of Aeronautics aircraft dispatcher training courses on Aviation English.

Alongside, knowledge in English language is also very encouraging while dealing with submarine affairs. The crew members and officials use this language as the first choice because the instructions about navigation are conveyed in this tongue.

The utilization of English words in daily life: -

The knowledge in English is not only important to get higher education or to know the critical issue of universal politics or diplomacy, it's really important to know the English tongue because so many daily used common words are in English. The use of English words in daily lives of general people of many countries cannot be denied including where English is not the native language. People use the names of gadgets of cars like clutch, gear, steering, wheels, lights, indicators, wipers, seats, belts windows, glasses, mirrors, signals etc. to home utensils as of plumbing like pipes, showers etc. cooking apparatus like cylinders, lighters, cookers etc., technological devices like TV, radio, mobile phone, telephone, computers, laptops, chargers etc.

The aerial logics are just some of the many one can contemplate to appreciate the significance of studying English. Barring, being functional English can offer people copious gratification. this will coerce them perceive sizeable when they discern that they can progress, conceivably slowly but unwaveringly.

\section{CONCLUSION: -}

I would conclude by affirming that excepting one's parent language, one requires to have a common terminology to liaise with others as well as share suggestions with them. English is one of the most commanding speech of the globe which is having its impression on every single discipline of exertion. English plays a part of common parlance betwixt all territories. Irrefragably, English plays a much pronounced role in the universe that it is unavoidable for people to neglect it completely. There is no contradicting people have been progressively noticing the significance of English speech. By getting expertise over English, one can share their concepts, comprehension, fact-finding etc. as well as flourish with the demanding universe.

\section{REFERENCES: -}

1. Bolinger, Dwight. (1968). Aspects of language. New York: Harcourt, Brace \& World Inc. Bose, M.N.K. (2007). A Text Book of English Language and Teaching (ELT) for Indian students (2 Ed.). Chennai: New Century book House.

2. Rajathurai Nishanthi, IJTSRD International Open Access Journal, No: 2456-6470, Volume- 3, Issue- 1, Nov- Dec 2018.

3. https://www.british-study.com/adults/10-reasons-to-learn-english.php

4. https://www.elc-schools.com/blog/4-reasons-why-learning-english-is-so-important/ 